\title{
Çarpan jetle ısı transferinde geometrik parametrelerin sayısal optimizasyonu: Yanıt yüzey yöntemi
}

\author{
Numerical optimization of geometric parameters in impinging jet heat transfer: Response \\ surface methodology
}

\author{
Ahmet Numan ÖZAKIN ${ }^{1, a}$, Faruk YEŞILDAL ${ }^{* 1, b}$ \\ ${ }^{I}$ Atatürk Üniversitesi, Mühendislik Fakültesi, Makine Mühendisliği Bölümü, 25240, Erzurum
}

$\ddot{O} z$

Bu çalı̧̧ada çarpan jet ile soğutmada parametrelerin etkisini belirlemek için Yanıt Yüzey Yöntemi (YYY) ile sayısal optimizasyon yapılmıştır. Nozul sayısı, kanat uzunluğu, kanat geometrisi ve nozul-yüzey mesafesi (H) faktörlerinin etkisi araştırılmıştır. Yanıt değiş̧keni olarak sıcaklık farkı alınmıştır. Sonuçta en etkin parametre kanat uzunluğu olarak elde edilmiştir. Optimum sonuçlar; nozul sayısı için 5 , kanat uzunluğu için $1.5 \mathrm{~cm}$, kanat geometrisi olarak silindir ve $\mathrm{H}$ için $2 \mathrm{~cm}$ olarak elde edilmiştir. Ayrıca, yanıt değişkeni olan sıcaklık farkı için bir matematiksel model geliştirilmiştir.

Anahtar kelimeler: Çarpan jet, Hesaplamalı akışkanlar dinamiği, Yanıt yüzey yöntemi

\begin{abstract}
In this study, numerical optimization was carried out with the Response Surface Method (RSM) to determine the effect of parameters in impinging jet cooling. The effects of nozzle number, fin height, fin geometry and nozzle to surface distance $(H)$ were investigated. The temperature difference was taken as the response variable. As a result, the most effective parameter was obtained as the fin height. Optimal results; 5 for the number of nozzles, $1.5 \mathrm{~cm}$ for the fin height, the cylinder fin geometry and $2 \mathrm{~cm}$ for $H$ distance. In addition, a mathematical model has been developed for the temperature difference determined as the response variable.
\end{abstract}

Keywords: Impinging jet, Computational fluid dynamic, Response surface method

\footnotetext{
*a Faruk YEŞiLDAL; fyesildal@atauni.edu.tr, Tel: (0442) 23145 01, orcid.org/0000-0002-7307-3556

${ }^{\mathrm{b}}$ orcid.org/0000-0002-2083-8703
} 


\section{Giriş \\ 1. Introduction}

Isı1 hedef yüzeyden etkili bir şekilde uzaklaştırmak için çarpan jetler sıklıkla uygulanan bir termal yönetim tekniğidir. Küçük bir alanda çok yüksek 1sı akısının üretildiği cihazların sıcaklığını kontrol etmek için kullanılan bir yöntemdir. Çarpan jetler, pasif kendinden uyarımlı jetler, aktif uyarıcıl jetler ve hibrit uyarımlı jetler gibi farklı tekniklerle elde edilebilir. Kendinden tahrikli jetlerin aktif yöntemleri dairesel, dönen ve süpüren jetleri içerirken, pasif olanlar darbeli ve sentetik jetleri içerir (Maghrabie, 2021). Çarpan jet teknikleri, gaz türbini kanatlarının soğutulması (Al-Hadhrami vd., 2011), farklı metallerin 1s1l işlemi, dokunun dondurulması için kriyocerrahi, cam (Monnoyer \&Lochegnies, 2008) ve metal işleme, tekstil ve kağıt kurutma, elektronik elemanların ve merkezi işlemci ünitesinin soğutulması, güneş enerjisi ve fotovoltaik sistemlerin soğutulması dahil olmak üzere çeşitli mühendislik uygulamaları için uygun hale getiren yüksek oranda 1s1 transferi sağlamak için kullanılabilir (Maghrabie, 2021). Endüstriyel uygulamalarda, çarpan jetler kullanılarak 1s1 ve kütle transferi önemli ölçüde arttırılabilir.

Çarpan jet ile 1s1 transferi; jet geometrisi, yönlendirme, nozul-yüzey mesafesi, kanatçık geometrisi, nozul dizilişi, jet çıkışının sınırlandırılması, nozul içine yerleştirilen türbülatörler gibi geometrik parametrelerin yanında debi, hız ve basınç gibi operasyonel parametrelere de bağlidır.

Mikroçiplerin çarpan jet ile soğutulmasına yönelik nümerik bir çalışma yürüten araştırmacılar, üç tarafı kapalı ve bir tarafı açık dikdörtgen kesitli kanallardaki sur ve dikdörtgen desende $1000 \mathrm{~W} / \mathrm{m}^{2}$ sabit 1s1 akılı bakır plakalı yüzeyleri tek bir hava jeti akışı ile soğutmuşlardır (Karabulut \& Alnak, 2020). Sonuçta $\mathrm{Re}=4000$ ve $\mathrm{H} / \mathrm{D}_{\mathrm{h}}=4$ için dikdörtgen desenli yüzeylerde sur desenli yüzeylere göre $\% 31.45$ daha yüksek ortalama $\mathrm{Nu}$ sayis1 elde ettiler.

Düşük Reynolds Sayısı rejiminde $(<1000)$ çoklu çarpan jet sisteminin 1sı transferi ve basınç özelliklerinin incelendiği çalışmada, 841 çarpan jetten oluşan bir sıralı konfigürasyonda, farklı jetplaka mesafeleri ve Reynolds sayılarında çalışmalar yürütülmüştür. Deneysel araştırmayı, jet çarpmasının fiziğini ve böyle bir sistem içindeki bitişik jetler arasındaki etkileşimi incelemek için sayısal bir araştırma ile de desteklenmiştir. CFD simülasyonlarının, ısı transfer katsayısını yaklaşık
$\% 10$ ve basınç düşüşünü yaklaşı $\% 20$ oranında fazla tahmin ettiği belirtilmiştir (Rao vd., 2009).

Başka bir araştırmada (Buzzard vd., 2017) özel pürüzlülük modellerinin çarpan jet dizisi soğutmasının etkinliğini ve yüzey 1S1 transferini artırma seviyelerini iyileştirmek için hedef yüzeyler üzerindeki etkileri incelenmiştir. Bunun için çarpan jetle soğutma artırımı için yüzey pürüzlülüğünün çeşitli boyutları, dağılımları, şekilleri ve modelleri kullanılmıştır. Farklı Re sayılarında $(900,1500,5000$ ve 11000) deneyleri dikdörtgen şeklinde farklı boyutlarda pürüzlülükler için yürütülmüştür. Lokal ve genel çarpan jet performanslarının, pürüzlülük elemanlarının modeline, dağılımına, düzenine, yüksekliğine ve ayrica jet Reynolds sayısına bağlı olduğu belirtilmiştir. Sonuçta hem laminer hem de türbülanslı jet Reynolds sayıları için, dikdörtgen küçük pürüzlülük durumlarında genellikle artan küçük pürüzlülük yüksekliği ile çizgi ortalamalı ve uzamsal ortalamalı Nusselt sayısında bir artış gösterdiği belirtilmiştir.

Jet geometrisinin etkisinin incelendiği başka bir çalışmada yazarlar (Caliskan vd., 2014) 1sı transfer karakteristiklerini deneysel ve teorik olarak incelemişlerdir. Eliptik ve dikdörtgen çarpan jet dizilerini incelediler. Hız ölçümlerini LaserDoppler Anemometresi ile, sicaklık ölçümlerini ise kızılötesi kamera ile aldılar. Deneyleri farklı en/boy oranları $(0.5,1,2)$, nozul-yüzey mesafeleri $(2 \ldots .10)$ ve $\operatorname{Re}$ sayllarında $(2000 \ldots 10000)$ yürüttüler. Çarpma bölgesinde Nusselt sayılarını eliptik jetler için dairesel jetten daha yüksek elde ettiler. Bunun büyük sürüklenme hızından ve eliptik jetin büyük ölçekli uyumlu yapısından kaynaklanabileceğini iddia ettiler. En iyi 1S1 transfer performansını eliptik jet düzenlemeleri ile elde ettiler. Ortalama Nusselt sayıs1 korelasyonlarını eliptik ve dikdörtgen jet geometrileri için elde ettiler. Ayrıca simülasyonla tüm jet geometrileri için hız dağılımlarını elde ettiler. Eksenel, radyal hız dağılımları ve türbülans kinetik enerjisi dağılımlarını hesapladılar. Sonuçları $\mathrm{Nu}-\mathrm{x} / \mathrm{d}$ grafikleri halinde sundular.

Türbülans, jetten jete ve jetten duvara etkileşimler, bu etkileşimlerin 1sı ve kütle transferleri üzerindeki dolaylı etkileri nedeniyle dönel akışların dinamikleri bazı avantajları ve dezavantajları ile farklıdır. Bu konuda birçok araştırma yapılmıştır.

Düz ve girdap jetlerin kademeli bir kombinasyonunun incelendiği bu çalışmada araştırmacılar (Wannassi \& Monnoyer, 2015) akış ayrıntılarına erişmek ve karmaşı 1 akış yapılarının yanı sıra soğutma havasının yaşadığı besleme ve 
egzoz fazları arasındaki güçlü bağlantıyı göstermek için akış ve 1sı transfer özelliklerini rapor ettiler. Girdap çoklu jetlerin termo-akışkan dinamiğinin anlaşılmasına olanak sağlamak için, belirli bir jet-jet mesafesi, $\mathrm{s} / \mathrm{D}=5$ ve nozul-plaka mesafesi $\mathrm{H} / \mathrm{D}=4$ için sayısal ve deneysel çalışma yürüttüler. Jetleri kademeli bir dizi olarak düzenlediler. Girdap jet düzeneğini kanatçık tipi bir jeneratörden elde ettiler. Farklı kanat yönleri ile farklı girdap yoğunluklarına sahip jetler elde ettiler. Dönel çarpan jetlerle elde edilen sonuçları aynı deneysel koşullarda dairesel çarpan jetlerle karşılaştırdılar. Hem sayısal hem de deneysel analiz ile hücre topolojisini ve çarpmada ortaya çıkan akışı gösterdiler. Her jetin, çarpma plakası üzerinde bağımsız bir soğutma alanına sahip olduğu sonucuna vardılar. Isı transfer hızının ve homojenliğin dönme üzerindeki bağımlılığını da açıkladılar. Sonuçta girdap hareketinin karıştırmayı nozul çıkışından kısa bir mesafede etkileyebileceğini, ancak yoğunluğunu hızla kaybettiğini ve bunun da duvar girişimine katkıyı sınırladığını belirttiler. Nuntadusit ve arkadaşları (Nuntadusit vd., 2012) $3 \times 3$ siralı düzenlemeye sahip birden çok dönel çarpan jetin (M-SIJ) yüzeyler üzerindeki akış ve 1sı transfer özelliklerini rapor ettiler. Deneyleri L/D $=4$ sabit nozul yüzey mesafesinde ve farklı nozullar arası mesafelerde $(\mathrm{S} / \mathrm{D}=2,4,6,8)$ yürüttüler. Nozullarda girdap sayıs1 0.4 olan bükülmüş bantlardan oluşan dönel jetler kullandılar. Sonuçları $\mathrm{Nu}-\mathrm{S} / \mathrm{D}$ ve $\mathrm{Nu}-\mathrm{X} / \mathrm{D}$ grafikleri halinde sundular. Sonuçta maksimum $\mathrm{Nu}$ sayısını $\mathrm{S} / \mathrm{D}=4$ için elde ettiler. $\mathrm{Bu}$ çalışmada yazarlar (Ianiro \& Cardone, 2012) sarmal sayısının, çarpan helezonik girdap hava jetinin düz bir levha üzerindeki duvar 1sı transferi dağılımı üzerindeki etkisini deneysel olarak analiz ettiler. Sicaklık ölçümlerini sabit Re sayısında (28000) 5 farklı girdap sayıs $1(0,0.2,0.4,0.6$ ve 0.8$)$ ve 5 farklı nozul-plaka mesafesi $(2,4,6,8$ ve 10$)$ için termal kamera (FLIR SC6000 LW) ve 1sitılmış ince folyo yüzeyden aldılar. Dönel çarpan jetlerle elde edilen sonuçları, aynı test koşullarında dairesel bir çarpma jeti ile elde edilenlerle karşılaştırdılar. Isı transfer hızının ve homojenliğinin girdap sayısına bağımlılığını da açıkladılar. Sonuçta çok kanallı jetin, dairesel çarpma jetine göre 1S1 transferinde genel bir artışa neden olduğunu, girdap hareketinin hızı azalttığını ve 1S1 transferinin homojenliğini arttırdığını belirttiler. Dönel çarpan jetlerle ilgili bir başka çalışmada araştırmacılar araştırmacılar (Ahmed vd., 2015), dönmenin sıkıştırılamaz, türbülanslı, dönen bir çarpan hava jeti için çarpma yüzey basıncı üzerindeki etkilerini deneysel olarak araştırdılar. Hız bileşenlerini ölçmek için hotwire anemometresi kullandılar. Çarpma yüzeyindeki statik basınçları ölçmek için çarpma plakasına gömme montajlı basınç musluklarına sahip bir dijital mikromanometre (TSI, model: 5815) kullandılar. Girdap sayısının (S), nozul-plaka mesafesinin $(\mathrm{H})$ ve Reynolds sayısının (Re) basınç dağılımına etkisini incelediler. Herhangi bir S için, basınç dağılımının düşük girdap sayıları için $(\mathrm{S}=$ 0.3 'e kadar) Re'den bağımsız olduğunu gösterdiler.

Bu çalışmada (Yakut vd., 2016) OHS-2 olarak adlandırılan altıgen kanatlı soğutucunun çarpan hava jeti 1sı ve akış özelliklerini deneysel olarak belirlediler. Ansys-Fluent ile sayısal olarak analiz ettiler. Nozul çapı, iki farklı Y/d mesafesi, 6 farklı akış hızı ve 3 farklı kanat yüksekliği için altıgen kanatçıklarda deneysel ve sayısal çalışma yürüttüler. Sonuçları $\mathrm{Nu}-\mathrm{Re}$ ve $\mathrm{Cp}_{\mathrm{x}, \mathrm{y}}-1 /\left(\mathrm{l}_{0} / 2\right)$ varyasyonları halinde sundular ve karşılaştırdılar. En yüksek Nusselt sayısını ve en yüksek basınç katsayısını $100 \mathrm{~mm}$ kanat yüksekliği ve $\mathrm{Y} / \mathrm{d}=1$ için elde ettiler. Son olarak, çarpan jet 1s1 transferinin deneysel ve sayısal sonuçlarından 1s1 transferi korelasyonları ürettiler.

Bir dizi çarpan jet üzerinde yürütülen sayısal çalışmada araştırmacılar (Penumadu \& Rao, 2017) Reynolds ortalamalı Navier-Stokes (RANS), kararsız Reynolds ortalamalı Navier-Stokes (URANS) ve çoklu çarpan jet dizisinde akış fiziğinin daha iyi anlaşılması için Büyük Eddy Simülasyonu (LES) yaklaşımlarını kullandılar. Simülasyonlar sonucunda, sistemdeki büyük basınç kaybının, meme girişindeki büzülme etkisinden ve viskoz kayıplardan kaynaklandığını gösterdiler.

Bir başka sayısal çalışmada araştırmacılar (OrtegaCasanova \& Granados-Ortiz, 2014) çarpan jetler ve üniform olmayan 1sıtılmış plakalar arasındaki 1sı transferini plakalar boyunca yüzey değişimlerinin (çukurlar ve tümsekler) etkisi altında iyileştirip iyileştiremeyeceğini analiz ettiler. Jet çıkışından bilinen bir $\mathrm{H}$ mesafesinde bulunan düz olmayan bir plaka üzerine iki farklı tipte eksenel simetrik türbülanslı jet çarpmasının sayısal simülasyonlarını yaptılar. Çalışmayı farklı plakalar, nozul-yüzey mesafeleri ve Reynolds sayılarında yürüttüler. Tüm plakada ısı transferinin artırılması gerektiğinde, toplam 1s1 transfer katsayısının düz bir plakanınkinden daha büyük veya en azından onunki kadar yüksek olduğunu ve çarpma plakalarının kullanılması gerektiğini tavsiye ettiler.

$\mathrm{Bu}$ çalışmada Diop ve arkadaşları verimli bir soğutma sağlamak için uygun hızda ve yeterli çarpışma mesafelerinde hava jet akışı ile 1sı transferini geliştirmeyi amaçladılar. Çalışmada H/D mesafesinin ve hızın farklı değerleri için 
deneyleri yürüttüler. Yüksek hızlı kamera ile akışı görüntülediler. Sonuçta, X/ D = 4, 7 ve 9 çarpma mesafelerinde, $15 \mathrm{~m} / \mathrm{s}$ hızında diğer değerlere göre en yüksek 1sı transfer katsayısının elde edildiğini gösterdiler (Diop vd., 2021). Tablo 1'de çarpan jet çalışmaları ve incelenen parametreler detaylı olarak sunulmuştur.

Tablo 1.Çarpan jet ile ilgili bazı çalışmalar

Table 1. Some studies in impinging jet

\begin{tabular}{|c|c|c|c|}
\hline İncelenen parametreler & Geometri & Bulgular & Yazar \\
\hline $\begin{array}{ll}- & \text { Nozul-yüzey mesafesi } \\
- & \text { Jet genişliği } \\
- & \text { Reynolds sayısı }\end{array}$ & Düz plaka & $\begin{array}{l}\text { Durma noktası civarında maksimum Nusselt } \\
\text { sayıları elde edilmiştir. }\end{array}$ & $\begin{array}{l}\text { (Ashforth- } \\
\text { Frost vd. } \\
\text { 1997) }\end{array}$ \\
\hline $\begin{array}{ll}\text { - } & \text { Jet en boy oranı } \\
\text { - } & \text { Reynolds sayıs1 }\end{array}$ & $\begin{array}{l}\text { Eliptik- } \\
\text { Dikdörtgen }\end{array}$ & $\begin{array}{l}\text { Çarpma bölgelerindeki eliptik jetler için Nusselt } \\
\text { sayılarını dairesel jetlerden daha büyük elde } \\
\text { ettiler }\end{array}$ & $\begin{array}{l}\text { (Caliskan } \\
\text { vd., 2014) }\end{array}$ \\
\hline 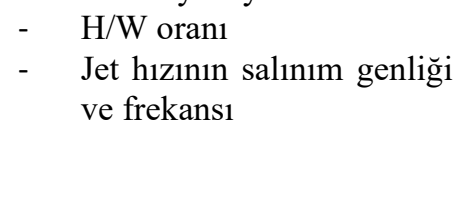 & $\begin{array}{l}\text { Paralel } \\
\text { sonsuz } \\
\text { levha }\end{array}$ & $\begin{array}{l}\text { Levhalar arası mesafenin artmasıyla, durma } \\
\text { noktası Nusselt sayısının azaldığını, } \\
\text { ancak H/W oranını 2'den büyük değerlerinde } \\
\text { Nusselt sayısındaki değişimin çok az olduğunu } \\
\text { gösterdiler. }\end{array}$ & $\begin{array}{l}\text { (Demircan \& } \\
\text { Türkoğlu, } \\
\text { 2010) }\end{array}$ \\
\hline $\begin{array}{ll}- & \text { Reynolds sayısı } \\
\text { - } & \text { Salınım genliği } \\
\text { - } & \text { Salınım frekansı }\end{array}$ & $\begin{array}{l}\text { Paralel } \\
\text { sonsuz } \\
\text { levha }\end{array}$ & $\begin{array}{l}\text { Artan Reynolds sayısı ile levha üzerindeki ıs1 } \\
\text { transferinde artış gözlediler. Bunun yanında } \\
\text { salınım frekansı ve genliğinin artması ile durma } \\
\text { noktası Nusselt } \\
\text { sayısının arttığını belirttiler. }\end{array}$ & $\begin{array}{l}\text { (Demircan \& } \\
\text { Türkoğlu, } \\
\text { 2007) }\end{array}$ \\
\hline $\begin{array}{ll}\text { - } & \text { Reynolds sayısı } \\
- & \mathrm{H} / \mathrm{D}_{\mathrm{h}} \text { oranı } \\
- & \text { Akı̧ yönlendiriciler }\end{array}$ & $\begin{array}{l}\text { Silindirik, } \\
\text { kare ve } \\
\text { üçgen }\end{array}$ & $\begin{array}{l}\text { Çarpan jet ile farklı geometride akış } \\
\text { yönlendiricilerin birlikte kullanıldığ durumda 1s1 } \\
\text { transferinde akış yönlendirici kullanılmamas1 } \\
\text { durumuna } \\
\text { göre } \% 28 \text { 'e kadar bir artış olduğunu gösterdiler. }\end{array}$ & $\begin{array}{l}\text { (Kilic \& } \\
\text { Baskaya, } \\
\text { 2017) }\end{array}$ \\
\hline $\begin{array}{ll}\text { - } & \text { h/d oranı } \\
\text { - } & \text { Reynolds sayısı } \\
\text { - } & \text { Türbülans şiddeti } \\
\text { - } & \text { Re sayısı } \\
\text { - } & \text { Jet dönme yoğunluğu } \\
\text { - } & \text { Türbülans şiddeti } \\
\text { - } & \text { Jet yüzey mesafesi }\end{array}$ & $\begin{array}{l}\text { Cr-Ni } \\
\text { paslanmaz } \\
\text { sac kanal } \\
\text { Isıtıllmış katı } \\
\text { yüzey }\end{array}$ & $\begin{array}{l}\text { Durma noktası Nusselt sayısı ile ortalama Nusselt } \\
\text { sayısı arasındaki farkın düşük olduğunu } \\
\text { belirttiler. } \\
\text { Boyutsuz parametrelerin bir fonksiyonu olarak } \\
\text { hem ortalama Nusselt sayısı hem de durma } \\
\text { noktası Nusselt sayısı için sayısal çalışmada } \\
\text { korelasyon elde etmişlerdir. }\end{array}$ & $\begin{array}{l}\text { (Çelik \& } \\
\text { Haydar, } \\
\text { 2010) } \\
\text { (Ortega- } \\
\text { Casanova, } \\
\text { 2012) }\end{array}$ \\
\hline
\end{tabular}

Çarpan jetlerle ilgili birçok optimizasyon çalışması vardır. Araştırmacılar (Barbosa vd., 2021) yürüttükleri parametrik çalışmada bir yüzeye çarpan çoklu hava jetleri üzerinde deneysel bir çalışma yapmak için Taguchi yöntemine dayalı bir bir Varyans Analizi (ANOVA) uyguladilar. Çalışmada jet-jet aralığı (S), jet deseni, nozul-plaka mesafesi $(\mathrm{H})$, Reynolds sayıs ve hedef plaka geometrisi parametrelerini incelediler. Deneyleri hedef plaka sabit ve hareketli iken yaptılar ve her iki durumda elde edilen sonuçları karşılaştırdılar. Sonuçlar, çoklu çarpan jet konfigürasyonunda 1s1 transferinin, kademeli bir konfigürasyon için $\mathrm{S}=$ $3 \mathrm{D}, \mathrm{H}=2 \mathrm{D}$ ve hem sabit hem de hareketli plakalar için daha yüksek bir Reynolds sayısı ile arttığını gösterdiler. Farklı bir kurutma optimizasyon çalışmasında araştırmacılar (Wang vd., 2016) bir hava jetli darbeli kurutucuda (AJID) soya küspesinin (Okara) kurutma sürecini optimize etmek için Yanıt Yüzey metodolojisini ve sentetik değerlendirme yöntemini uyguladılar.
Optimizasyonda işlem faktörleri olarak hava sıcaklığ $\left(50-70{ }^{\circ} \mathrm{C}\right)$, hava hızı $(1.3-2.3 \mathrm{~m} / \mathrm{s})$ ve numune yükleme yoğunluğunu $\left(3-4 \mathrm{~kg} / \mathrm{m}^{2}\right)$ dikkate aldılar. Kurutma hızı, renk, tripsin inhibitör aktivitesi, soya izoflavon içeriği ve antioksidan aktiviteyi kalite parametreleri olarak değerlendirdiler. $\mathrm{Bu}$ sayısal optimizasyon çalışmasında araştırmacılar (Lam \& Prakash, 2017) farklı Reynolds sayısı (Re), Hiz Oranı (VR) ve Kanal Yüksekliği (H/L) değerleri için bir dizi hava jeti ile çarpmalı soğutma sisteminde akışkan akışı, 1S1 transferi ve entropi üretimini incelediler. Jet (hem birincil hem de ikincil) ve ortam sivisının arayüzü boyunca, kesme kuvvetlerinin kararsızlaştırıcı etkisinin, momentum difüzyonunun dengeleyici etkisinin üstesinden geldiğini gözlemlediler. Son olarak, çarpan jet soğutma sisteminin optimum konfigürasyonlarını elde etmek için Çok Amaçlı Genetik Algoritma (MOGA) uyguladılar. Yüzey ortalamalı Nusselt sayısını $\left(\overline{N u_{o v}}\right)$ ve küresel toplam entropi üretimini 
$\left(S_{t o t, \Omega}\right)$ performans parametresi olarak belirlediler. Araştırmacılar (Yildizeli \& Cadirci, 2020) pnömatik taşıma sistemlerinde çoklu çarpan jet parametrelerinin optimizayonu için genetik algoritma ile sayısal bir çalışma yürütmüşlerdir. Optimizasyon sürecinin, temassız taşıma sisteminin genel performansını iyileştirmek için yararlı bir araç olduğunu belirttiler.

Çoklu çarpan jet, soğutma ve 1sıtma performansını etkileyen çeşitli operasyonel ve geometrik parametreleri içeren karmaşık bir isı transfer sürecidir. $\mathrm{Bu}$ çalışmada çarpan hava jeti ile 1s1 transferini etkilediği bilinen bazı önemli parametrelerin tekli, üçlü ve beşli çarpan jet nozul konfigürasyonları; farklı kanatçık yüksekliklerinde kare, silindir ve altıgen profilli kanatçıklı yüzeyler için optimizasyonu amaçlanmıştır. Bunun için Yanıt Yüzey Yöntemi ile Yüz Merkezli Merkezi Kompozit Tasarım yöntemi uygulanmıştır. Minitab 18 Programı ile oluşturulan 31 farklı analiz Fluent ile sayısal olarak yapılmıştır.

\subsection{Yanıt yüzey yöntemi (YYY) ve deney planı 1.1.Response surface methodology and experimental plan}

YYY, tüm bağımsız değiş̧kenleri bütünleştiren ve sonunda bir çıktının teorik değerini verebilecek bir denklem kümesi bulmak için deneyden gelen veri girişini kullanan uygun deney tasarımı geliştirir. Çıktılar, iyi tasarlanmış regresyon deneyleri ve matematiksel modelden elde edilen sonuçlar ile elde edilir (Gelis \& Akyurek, 2021).

YYY, incelenen ilgili alanın hesaplama sonuçlarında parametrelerin optimal durumunu elde etmek için kullanılır ve ayrıca belirtilen parametreler arasındaki etkileşimi de içerir. $\mathrm{Bu}$ parametreler üç seviyede seçilir. Tablo 2'de nümerik analizi yapılacak parametreler ve seviyeleri verilmiştir. Çalışmada silindir, altıgen ve kare olmak üzere üç farklı kanat geometrisi; 0.5, 1 ve $1.5 \mathrm{~cm}$ kanat uzunluğu; 1,3 ve 5 nozul sayısı ile 2,4 ve $6 \mathrm{H}$ mesafesi belirlenmiştir.

Tablo 1. Parametreler ve seviyeleri

Table 2. Parameters and their levels

\begin{tabular}{cccc}
\hline Parametre & Seviye 1 & Seviye 2 & Seviye 3 \\
\hline Nozul sayısı & 1 & 3 & 5 \\
Kanat uzunluğu & 0.5 & 1 & 1.5 \\
$\begin{array}{c}(\mathrm{cm}) \\
\text { Kanat } \\
\text { geometrisi }\end{array}$ & Silindir & Altıgen & Kare \\
H mesafesi $(\mathrm{cm})$ & 2 & 4 & 6 \\
\hline
\end{tabular}

Tablo 2 de görüldüğü gibi her bir parametre 3 farklı düzeyde incelenmiştir. Konvansiyonel deney tasarım yöntemlerinden tam faktöriyel tasarım ile $4^{3}=64$ analiz yapmak yerine, parametreler arasındaki kompozit etkilerin de incelenebildiği Merkezi Kompozit Tasarım (CCD) kullanılarak sadece 31 analiz yapılmıştır (Tablo 3). Suralı deneyler gerektiğinde Merkezi Kompozit Tasarım'ın kullanımı yararlıdır.

Operasyonel ve geometrik faktörlerin optimizasyonu ile 1sı transferini maksimize etmek için RSM'yi kullandık. Bu çalışmada çeşitli deneysel faktörlerin sicaklık farkı üzerine etkisi değerlendirilmiştir. Sıcaklık farkı kararlı halde yüzey sıcaklığı ile akışkan sıcaklığı arasındaki farktır.

CFD analizlerinden elde edilen sıcaklık fark1 verileri, deney planında Minitab 18 programında analiz edilmiştir. İkinci dereceden yanıt yüzeyi (YY) modeli Tablo 3'te çizelgelenen deney tasarımının her faktör düzeyindeki kombinasyonu için ölçülen yoğunluk (yanıt) için varyans analizi (ANOVA) kullanılarak değerlendirilmiştir.

\subsection{HAD prosedürü \\ 1.2. CFD procedure}

Farklı parametrelerin (nozul sayısı, kanatçık uzunluğu, kanatçık geometrisi ve nozul-yüzey mesafesi) 1S1 transfer karakteristiklerine olan etkisini incelemek amaciyla yapılan sayısal çözümlemelerde hava sıcaklığı sabit $293.15 \mathrm{~K}$ ve hızı ise farklı nozul geometrilerinde eşit debi sağlamak amaciyla nozul girişinde sabit $10 \mathrm{~m} / \mathrm{s}$ olarak tanımlanmıştır. Soğutulması gereken eleman olarak 40x40x3 $\mathrm{mm}$ boyutlarına sahip alüminyum levha kullanılmıştır. Alüminyum levha üzerine $5 \mathrm{~mm}, 10 \mathrm{~mm}$ ve $15 \mathrm{~mm}$ yüksekliklere sahip kare, altıgen ve silindirik kanatçıklar yerleştirilmiştir. Kanatçıklar levha üzerinde eşit sayıda 25 'er adet ve farklı kanatçık geometrileri için eşit yüzey alanı oluşturacak şekilde $5 \mathrm{~mm}, 10$ $\mathrm{mm}$ ve $15 \mathrm{~mm}$ yüksekliklere sahip ve sirasiyla $2600 \mathrm{~mm}^{2}, 3600 \mathrm{~mm}^{2}$ ve $4600 \mathrm{~mm}^{2}$ olarak belirlenmiştir. HAD analizleri için oluşturulan kontrol hacimleri Şekil 1'de görülmektedir. 
Tablo 3. YYY deney planı

Table 3. RSM experimental layout

\begin{tabular}{|c|c|c|c|c|c|}
\hline \multirow[b]{2}{*}{ Deney No } & \multicolumn{4}{|c|}{ Parametreler } & \multirow{2}{*}{$\begin{array}{c}\text { Tepki Değişkeni } \\
\Delta \mathrm{T}\end{array}$} \\
\hline & Nozul sayısı & Kanat uzunluğu & Kanat geometrisi & H mesafesi & \\
\hline 1 & 1 & 1.5 & Kare & 4 & 6.76 \\
\hline 2 & 1 & 1 & Altigen & 3 & 8.35 \\
\hline 3 & 5 & 0.5 & Kare & 2 & 8.49 \\
\hline 4 & 1 & 1.5 & Kare & 2 & 7.31 \\
\hline 5 & 1 & 1.5 & Silindir & 2 & 6.44 \\
\hline 6 & 3 & 1 & Altigen & 3 & 8.15 \\
\hline 7 & 5 & 1.5 & Silindir & 4 & 7.49 \\
\hline 8 & 3 & 1 & Altigen & 3 & 8.15 \\
\hline 9 & 3 & 1 & Silindir & 3 & 6.78 \\
\hline 10 & 5 & 0.5 & Silindir & 2 & 7.80 \\
\hline 11 & 1 & 1.5 & Silindir & 4 & 6.81 \\
\hline 12 & 3 & 1 & Altıgen & 4 & 8.64 \\
\hline 13 & 1 & 0.5 & Silindir & 2 & 6.60 \\
\hline 14 & 5 & 1.5 & Kare & 2 & 2.80 \\
\hline 15 & 3 & 1 & Altigen & 3 & 8.15 \\
\hline 16 & 5 & 1 & Altigen & 3 & 8.55 \\
\hline 17 & 5 & 0.5 & Silindir & 4 & 9.28 \\
\hline 18 & 3 & 1.5 & Altigen & 3 & 7.75 \\
\hline 19 & 5 & 1.5 & Kare & 4 & 8.38 \\
\hline 20 & 3 & 1 & Altigen & 3 & 8.15 \\
\hline 21 & 3 & 0.5 & Altıgen & 3 & 9.48 \\
\hline 22 & 5 & 1.5 & Silindir & 2 & 6.66 \\
\hline 23 & 5 & 0.5 & Kare & 4 & 11.34 \\
\hline 24 & 3 & 1 & Altigen & 3 & 8.15 \\
\hline 25 & 5 & 1 & Altigen & 3 & 8.15 \\
\hline 26 & 1 & 0.5 & Kare & 4 & 10.10 \\
\hline 27 & 3 & 1 & Altigen & 2 & 7.67 \\
\hline 28 & 3 & 1 & Alt1gen & 3 & 8.15 \\
\hline 29 & 3 & 1 & Kare & 3 & 8.42 \\
\hline 30 & 1 & 0.5 & Kare & 2 & 9.37 \\
\hline 31 & 1 & 0.5 & Silindir & 4 & 6.76 \\
\hline
\end{tabular}

Kontrol hacimleri oluşturularak gereken tanımlamalar yapıldıktan sonra ilgili kontrol hacimleri için mesh hücreleri oluşturulmuştur. Çalışmada öncelikle 500.000 civarında mesh yapısı oluşturularak "Orthogonal Quality" \%90 civarına ulaştığı noktada tekli, üçlü ve beşli nozullara sahip kontrol hacimleri için sırasıyla 950.000, 1.000.000 ve 1.055 .000 civarında mesh oluşturulmuştur. Ulaşılan bu mesh sayılarından sonra mesh geometrilerinin belirli kısımlarda küçültülerek mesh sayısında yapılabilecek artışın sonuçlarda değişikliğe sebep olmadığı görülmüştür. Şekil 2'de oluşturulan mesh yapısı görülmektedir.

$\mathrm{Bu}$ çalışmada alüminyum levhanın alt kısmından sürekli $1000 \mathrm{~W} / \mathrm{m}^{2}$ 1S1 akısı tanımlanarak ve türbülans modeli olarak " $\mathrm{k}-\mathrm{E}$ RNG" modeli ile "Enhanced Wall Functions" şartları kullanılmıştır. HAD analizleri aşağıda maddeler halinde belirtilen kabuller ve sınır şartlarında gerçekleştirilmiştir.

- Akışkan olarak özellikleri zaman ve konumla değişmeyen $(\mathrm{Ma}<0,3)$ hava kullanılmıştır.
- Kontrol hacmine giren ve çıkan hava debisi süreklidir.

- Kontrol hacmi kararlıdır.

- Yer çekimi göz ardı edilmiştir.

Yukarıda belirtilen kabullerle birlikte HAD analizlerinde aşağıda verilen korunum denklemleri kullanılmıștır. Süreklilik denklemi;

$\frac{\partial \rho}{\partial t}+\frac{\partial \rho u}{\partial x}+\frac{\partial \rho v}{\partial y}+\frac{\partial \rho w}{\partial z}=0$

Momentumun korunumu denklemi;

$\frac{\partial \rho}{\partial t}+\vec{\nabla} \cdot(\rho \vec{V})=\frac{\partial \rho}{\partial t}+\vec{V} \cdot \vec{\nabla} \rho+\rho \vec{\nabla} \cdot \vec{V}=0$

enerji denklemi;

$\rho c_{v} \frac{d T}{d t}=k \nabla^{2} T+\Phi$

şeklinde ifade edilebilir. 


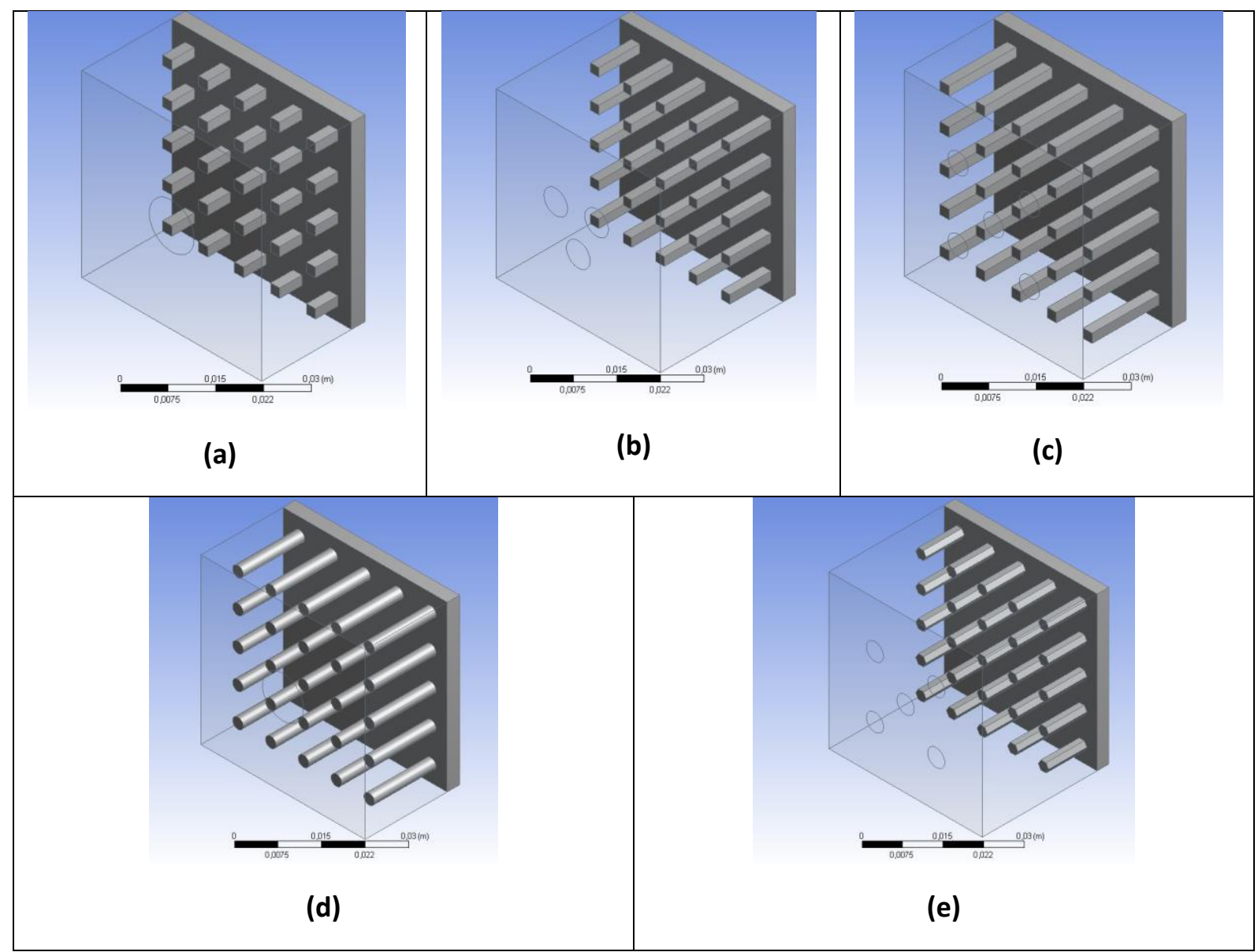

Şekil 1. Farklı geometriler ve nozul sayıları için kontrol hacimleri (a) tekli nozul-kare, (b) üçlü nozul-kare, (c) beşli nozul-kare, (d) tekli nozul-silindirik, (e) beşli nozul-altıgen

Figure 1. Control volumes for different geometries and number of nozzles (a) single nozzle-square, (b) triple nozzle-square, (c) quintuple nozzle-square, (d) single nozzle-cylindrical, (e) quintuple nozzle-hexagonal

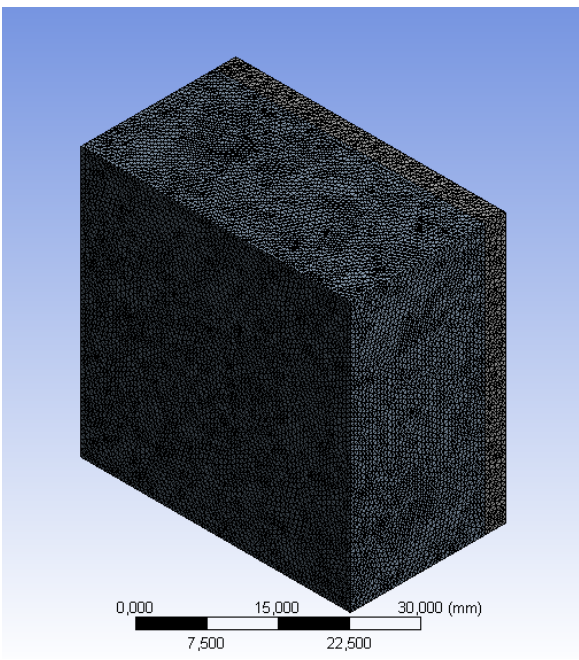

Şekil 2. İlgili kontrol hacimleri için oluşturulan mesh görünümü

Figure 2. Mesh view generated for control volumes

\section{Bulgular ve tartışma}

2. Results and discussion

Pareto grafiği (Şekil 3) etkilerin göreceli büyüklüğünü ve ana, kare ve etkileșim etkilerinin istatistiksel önemini karşılaştırmak için kullanılır. Etkiler, azalan mutlak değerler sırasına göre çizilir. Grafikteki referans çizgisi, hangi etkilerin önemli olduğunu gösterir. Bu referans çizgisinin ötesine geçen herhangi bir etki istatistiksel olarak önemlidir.

Şekil 3'teki Pareto grafiği sonuçlarına göre, sırasıyla; kanat uzunluğu (B), H mesafesi (D), kanat uzunluğu ve kanat geometrisinin bileşik etkisi (BC), nozul sayısı ve $\mathrm{H}$ mesafesinin bileşik etkisi (AD), kanat geometrisi (C), nozul sayısı ve kanat geometrisin bileşik etkisi (AC), nozul sayısı ve kanat uzunluğunun bileşik etkisi (AB) ve kanat geometrisi ve $\mathrm{H}$ mesafesinin bileşik etkisinin (CD) istatistiksel olarak anlamlı olduğu görülmektedir. Kanat uzunluğunun en büyük etkiye sahip olduğu, kanat geometrisi ve $\mathrm{H}$ mesafesinin ise en düşük etkiye sahip olduğu görülmektedir. 


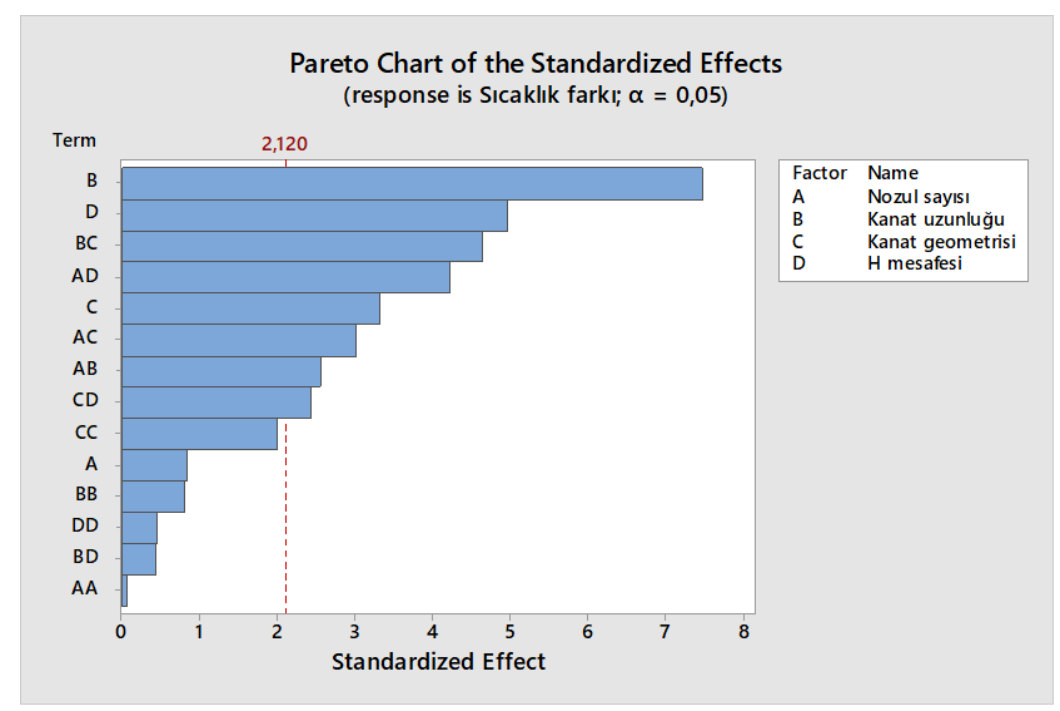

Şekil 3. Pareto grafiği

Figure 3. Pareto chart

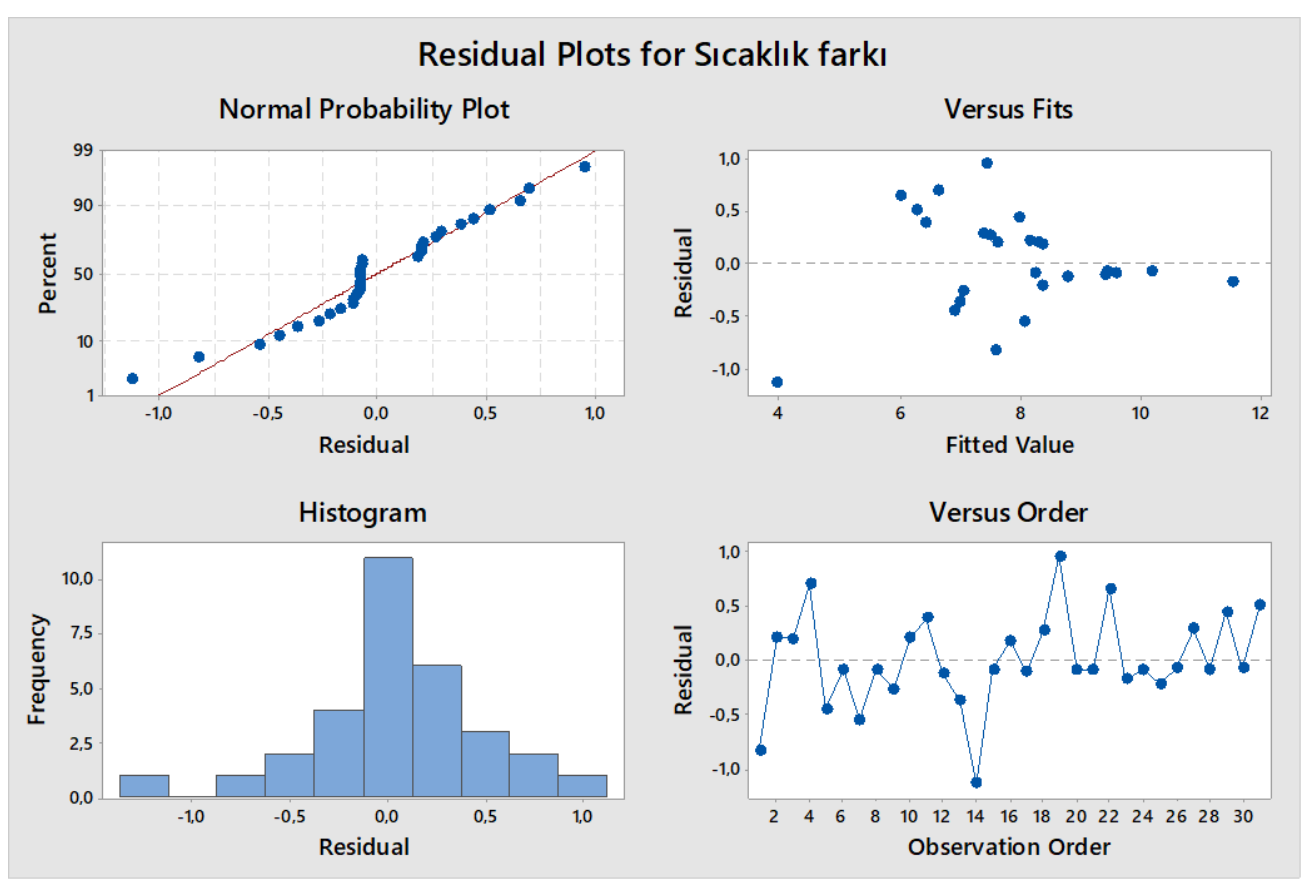

Şekil 4. Kalıntı grafiği

Figure 4. Residual plots

Normal olasılık grafiğindeki ortogonal çizgi, modelden alınan değerlerin ve sayısal analiz sonuçlarının örtüştüğü noktaları temsil eder. $\mathrm{Bu}$ çizgiden uzaklaşmak, model ile sayısal analiz arasında bir fark olduğu anlamına gelir. Minimum sıcaklık farkı için oluşturulan modelin verdiği sonuçlar ile sayısal analiz sonuçlarının iyi bir uyum içinde olduğu görülmektedir (Şekil 4). Kalıntılara karşı gözlem sırasını gösteren grafiğe göre, deney planında 31 deney için model ile deney arasındaki fark1 gösteren artık değerler gösterilmiştir. Pozitif bir artık değer, model tarafindan verilen değerin deneyde elde edilen değerden daha küçük olduğunu gösterir. Artık değer negatifse, modele göre değerin ve sayısal analiz değerinin birbirine yakın olduğu anlamına gelir. Grafikten görüldüğü gibi artıkların pozitif veya negatif olması modelin parametrelerle ilişkisinin güçlü olduğunu ve sayısal analiz değerlerinin birbirine yakın olduğunu göstermektedir. 


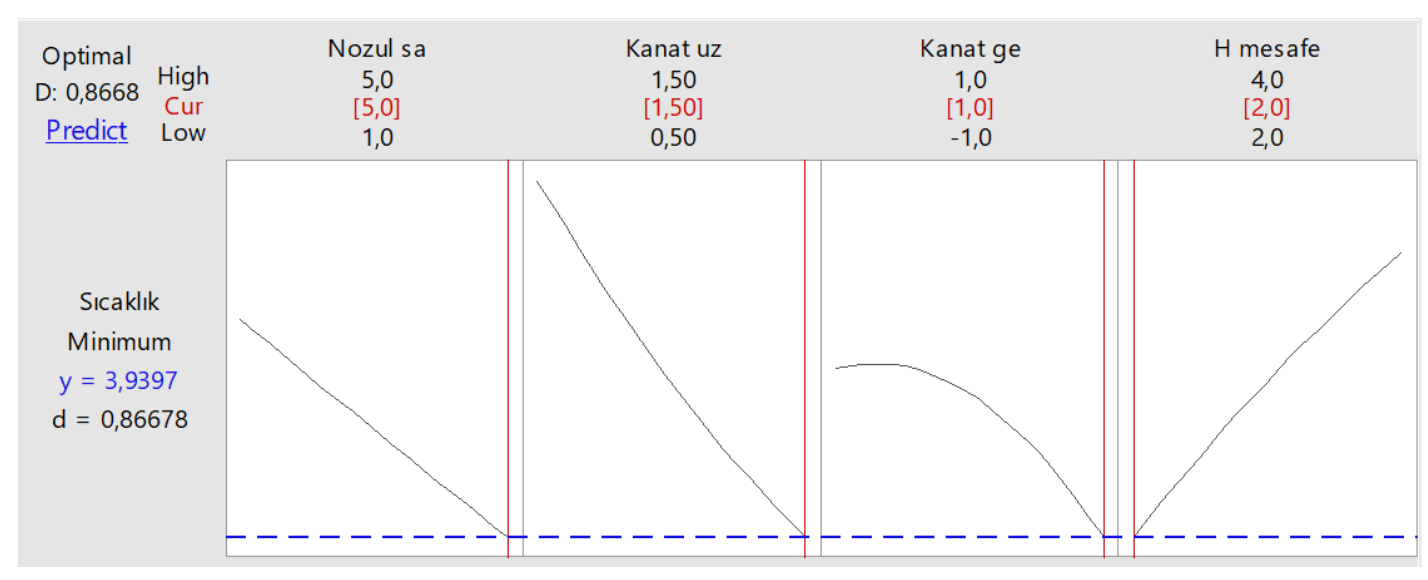

Şekil 5. Optimizasyon grafiği

Figure 5. Optimization plot

Çalışmada dikkate alınan üç faktöre dayalı olarak optimize edilmiş sıcaklık farkını belirlemek için model D-optimalite kriterini kullanmıştır. Şekil $5^{\prime}$ te gösterildiği gibi, $3.9397^{\circ} \mathrm{C}$ 'lik bir sıcaklık farkı ile en yüksek optimizasyon sonucu olarak 0.8669'lik bir D-optimalitesi elde edilmiștir. Optimum değerler ise Tablo 4'te verilmiştir. D değeri, maksimum hedef fonksiyon değeri anlamına gelir. Hedef fonksiyonunun optimum değerinin modelden elde edilebilecek maksimum değere oranını temsil eder. Ayrıca Şekil 5, parametreler ile optimal olarak hesaplanan değerlerin kesişimini göstermektedir (Yesildal vd., 2021).

Tablo 4. Optimum değerler

Table 4. Optimum values

\begin{tabular}{cc}
\hline Parametre & Optimum değer \\
\hline Nozul sayısı $(\mathrm{N})$ & 5 \\
Kanat uzunluğu $\left(\mathrm{h}_{\mathrm{k}}\right)$ & $1,5 \mathrm{~cm}$ \\
Kanat geometrisi $(\mathrm{KG})$ & Silindir \\
H mesafesi & $2 \mathrm{~cm}$ \\
\hline
\end{tabular}

RSM kullanılarak deneysel parametrelerin amaç fonksiyonu üzerindeki etkileri belirlenebilir ve elde edilen matematiksel model aracıllğıyla performans özellikleri arasında ilişkiler kurulabilir. Analiz sonucunda bir matematiksel model elde edilmiştir. Daha önce nozul sayısı $(N)$, kanat uzunluğu $\left(h_{k}\right)$, kanat geometrisi (KG) ve $\mathrm{H}$ sicaklık farkını etkileyen parametreler olarak belirlenmişti. Yanıt modeli oluşturmak için gerekli veriler Yüz Merkezli Merkezi Kompozit Tasarım (CCD) ile elde edilmiş ve sistemden alınan doğrulama test verileri RSM ile elde edilen matematiksel model kullanılarak karşılaştırılmıştır. Aşağıdaki denklem (Denklem 4), sıcaklık farkı $(\Delta \mathrm{T})$ için geliştirilmiş ikinci dereceden polinom modelini göstermektedir.

$$
\begin{aligned}
& \Delta T=9.86-0.53 N-3.67 h_{k}+1.429 K G+ \\
& 0.62 H+0.0046 N * N+1.17 h_{k} * h_{k}- \\
& 0.722 K G * K G-0.166 H * H-0.379 N * h_{k}- \\
& 0.2238 N * K G+0.3128 N * h_{k}-1.375 h_{k} * \\
& K G+0.126 h_{k} * H+0.36 K G * H
\end{aligned}
$$

Bir Yanıt Yüzey modeli, incelenen parametreler ile yanıt değişkeni arasındaki işlevsel ilişkiyi tanımlar ve yeterince iyi tanımlayamadığında bir uyumsuzluk meydana gelebilir. Uyumsuzluk testi, seçilen modelin gözlemlenen verileri açıklamak için yeterli olup olmadığını belirlemek için tasarlanmıştır. Oluşturulan model ile deneysel verilerin etkileşimini belirlemek için $P$ değeri önem düzeyi ile karşılaştırılır. Bu çalışmada, $\alpha=0,05$ anlamlılık düzeyi tercih edilmiştir. Model için 0,05 'ten küçük ilişkili $\mathrm{P}$ değerleri model terimlerinin istatistiksel olarak anlamlı olduğunu, 0,05 'ten büyük $\mathrm{P}$ değerleri ise model terimlerinin önemsiz etkileri olduğunu gösterir. Tepki değişkenimiz sıcaklık farkı için ANOVA tablosu Tablo 5'te gösterilmiştir. 
Tablo 5. Tepki değişkeni $(\Delta \mathrm{T})$ için ANOVA tablosu

Table 5. ANOVA table for response variable $(\Delta T)$

\begin{tabular}{clllll}
\hline Source & DF & Adj SS & Adj MS & F-Value & P-Value \\
\hline Model & 14 & 57.0489 & 4.0749 & 11.62 & 0.000 \\
Linear & 4 & 32.3694 & 8.0924 & 23.07 & 0.000 \\
A & 1 & 0.2488 & 0.2488 & 0.71 & 0.412 \\
B & 1 & 19.6460 & 19.6460 & 56.02 & 0.000 \\
C & 1 & 3.8716 & 3.8716 & 11.04 & 0.004 \\
D & 1 & 8.6030 & 8.6030 & 24.53 & 0.000 \\
Square & 4 & 3.1145 & 0.7786 & 2.22 & 0.113 \\
A*A & 1 & 0.0012 & 0.0012 & 0.00 & 0.955 \\
B*B & 1 & 0.2301 & 0.2301 & 0.66 & 0.430 \\
C*C & 1 & 1.3972 & 1.3972 & 3.98 & 0.063 \\
D*D & 1 & 0.0736 & 0.0736 & 0.21 & 0.653 \\
2-Way Interaction & 6 & 21.4737 & 3.5789 & 10.20 & 0.000 \\
A*B & 1 & 2.2945 & 2.2945 & 6.54 & 0.021 \\
A*C & 1 & 3.2068 & 3.2068 & 9.14 & 0.008 \\
A*D & 1 & 6.2638 & 6.2638 & 17.86 & 0.001 \\
B*C & 1 & 7.5666 & 7.5666 & 21.57 & 0.000 \\
B*D & 1 & 0.0634 & 0.18 & 0.676 \\
C*D & 1 & 2.0786 & 5.93 & 0.027 \\
Error & 16 & 2.0786 & 0.3507 & & 0.000 \\
Lack-of-Fit & 10 & 5.6116 & 0.5532 & 41.70 & \\
Pure Error & 6 & 5.5320 & 0.0133 & & \\
\hline Total & 30 & 0.0796 & & & \\
\hline
\end{tabular}

Yanıt yüzey yöntemi ile elde edilen optimum soğutma parametreleri kullanılarak HAD analizlerinde elde edilen görüntüler Şekil 5, Şekil 6 ve Şekil 7 ile verilmiștir.

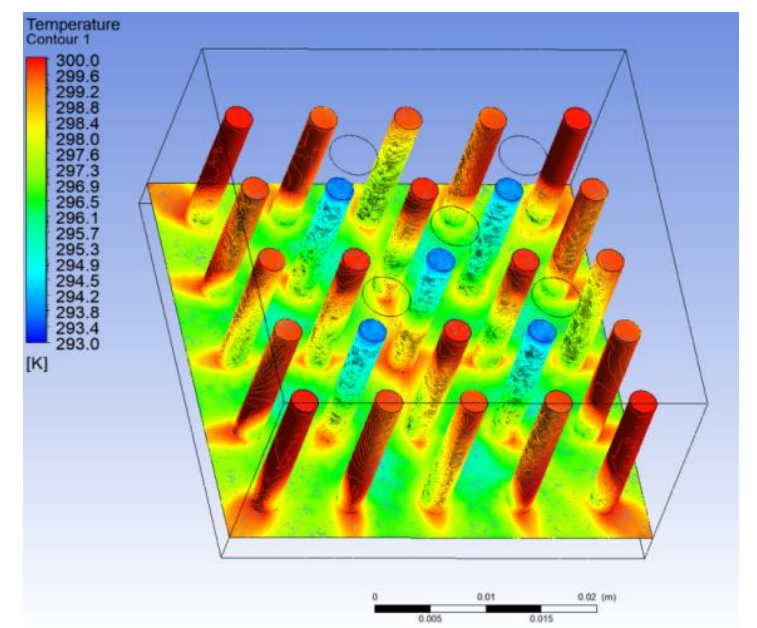

Şekil 6. Optimum parametreler kullanılarak elde edilen sıcaklık dağılımı

Figure 6. Temperature distribution obtained using optimum parameters

Şekil 6 incelendiğinde nozulların hemen alt kısmında kalan kanatçıkların diğer kanatçıklara kıyasla daha fazla sıcaklık gradyeni oluşturduğu görülmektedir. Akışın tek bir nozul yerine eşdeğer beş eş nozuldan verilmesi soğutma performansını artırmaktadır. Soğutulan alüminyum levha üzerindeki sıcaklık dağılımı incelendiğinde ise kanatçıklar sebebiyle akışın ulaşamayıp ölü nokta oluşturduğu kısımlarda sıcaklık daha yüksek seviyelere ulaşmıștır. $\mathrm{Bu}$ durum Şekil 6 incelendiğinde daha net bir şekilde görülmektedir. Şekil 6' da kanatçıkların oluşturduğu ölü bölgeler Şekil 5'te daha yüksek sicaklık olarak ortaya çıkmıştır. Benzer şekilde geometride orta kısımda bulunan nozulun altındaki kanatçık etrafında diğer kanatçıklara nispeten daha yüksek sicaklık görülmektedir. $\mathrm{Bu}$ gradyen oluşumunun sebebi diğer dört nozulun sebep olduğu akışın ortadaki nozul ile karışarak olumsuz etki göstermesidir.

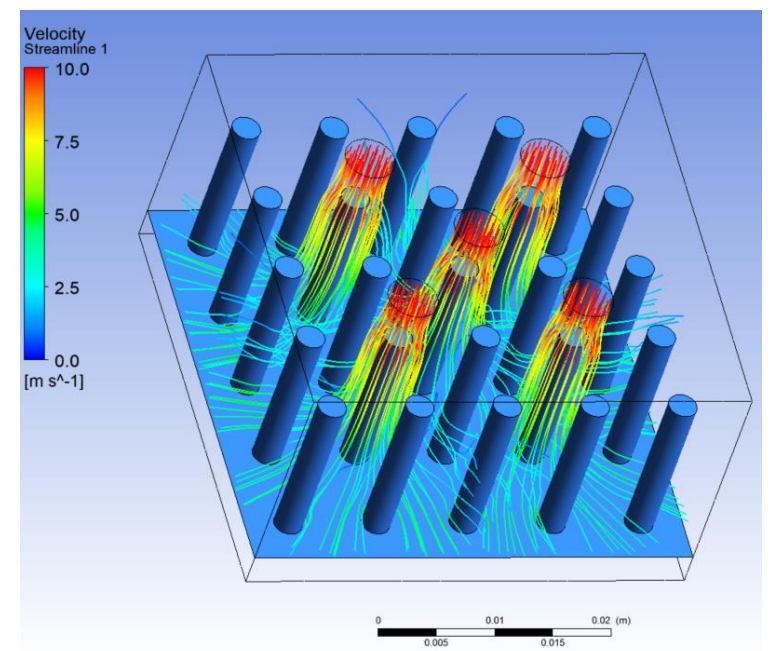

Şekil 7. Optimum parametreler kullanılarak elde edilen akım iplikçikleri

Figure 7. Streamlines obtained using optimum parameters 
Türbülans kinetik enerjisi, türbülanslı akıştaki girdaplarla ilişkili birim kütle başına ortalama kinetik enerjidir. Hızın farklı yönlerde oluşturduğu dalgalanmalarla karakterize edilen bu enerji sayısal analizlerde $\mathrm{k}-\boldsymbol{E}$ türbülans modeline göre hesaplanmıştır. Türbülans kinetik enerjisi (TKE) üç koordinattaki hız bileşenlerinin varyanslarının toplamının yarısıdır.

$T K E=\frac{1}{2}\left[\overline{\left(u^{\prime}\right)^{2}}+\overline{\left(v^{\prime}\right)^{2}}+\overline{\left(w^{\prime}\right)^{2}}\right]$

Şekil 8'de görülen türbülans kinetik enerji gradyeni incelendiğinde nozulların hemen altlarında bulunan kanatçıklar üzerinde daha fazla bir kinetik enerji değişimi görülmektedir. Bu kinetik enerji gradyenleri ortadaki nozulun çarptığı kanatçığın ve diğer kanatçıkların belirli kısımlarında daha fazladır. Bu kinetik enerji gradyen yığılmasının sebebi nozulların birbirlerini etkilemesidir. Bahsi geçen enerji yı̆̆ılmasının önüne geçebilmek için nozullar birbirlerinden daha uzak olarak konumlandirılabilir. Ancak bu durumun 1sı transfer karakteristiğine nasıl bir etki oluşturacağını belirlemek için farklı deneyler yapılması gerekmektedir.

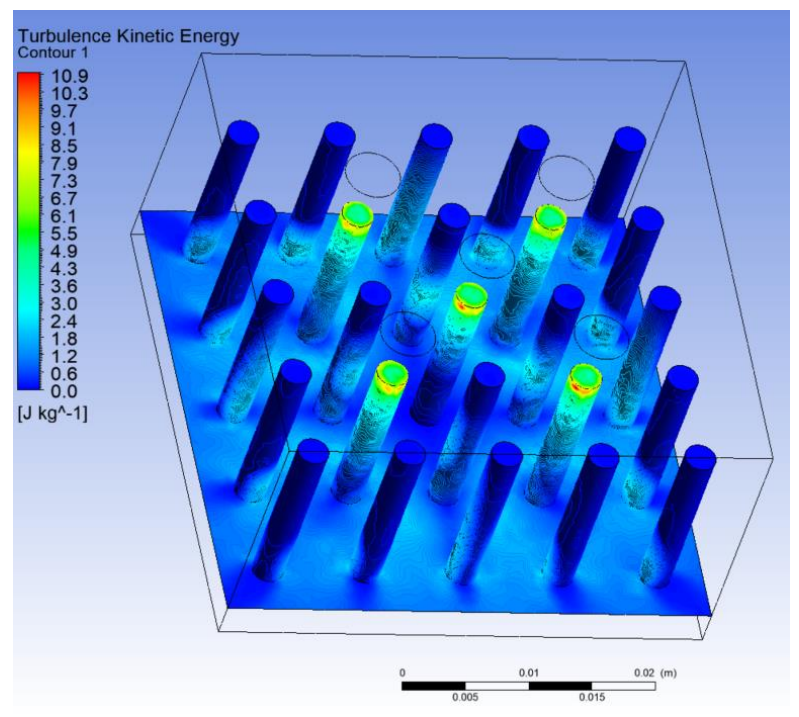

Şekil 8. Optimum parametreler kullanılarak elde edilen Türbülans Kinetik Enerji gradyeni

Figure 8. Turbulent kinetic energy gradient obtained using optimum parameters

\section{Tartıșma ve sonuçlar}

\section{Discussion and conclusions}

$\mathrm{Bu}$ çalışmada çarpan jet ile metal soğutmada etkin parametrelerin optimum değerlerini belirlemek ve matematiksel model oluşturmak için Yanıt Yüzey Yöntemi (YYY) kullanılmıştır. Hedef fonksiyon olarak (yanıt değişkeni) sıcaklık farkı alınmıştır.
Sonuçta en etkin parametre kanat uzunluğu olarak elde edilmiştir. Kanat geometrisi ve $\mathrm{H}$ mesafesinin bileşik etkisinin (CD) minimum etkiye sahip olduğu sonucuna varılmıştır. Optimum sonuçlar; 5 nozul sayısı, $1.5 \mathrm{~cm}$ kanat uzunluğu, silindir kanat geometrisi ve $2 \mathrm{~cm} \mathrm{H}$ mesafesi olarak elde edilmiştir. İlaveten bağımsız parametrelerle temsil edilen matematiksel bir model sunulmuştur.

\section{Yazar katkısı}

Author contribution

Bu çalışmada, birinci yazar Ahmet Numan Özakın HAD modellemesi, analizi ve yorumlarmı yapmıştır. İkinci yazar Faruk Yeşildal ise Yanıt yüzey yöntemi ve optimizayon analizi ve grafiklerin yorumlanması ile ağırlıklı olarak ilgilenmiştir. Yazarlar makalenin diğer kısımlarına da eşit katkı sunmuşlardır.

\section{Etik beyanı}

Declaration of ethical code

$\mathrm{Bu}$ makalenin yazarları, bu çalışmada kullanılan materyal ve yöntemlerin etik kurul izni ve / veya yasal-özel izin gerektirmediğini beyan etmektedir.

\section{Çıkar çatışması beyanı \\ Conflicts of interest}

Yazarlar herhangi bir çıkar çatışması olmadığını beyan eder.

\section{Kaynaklar \\ References}

Ahmed, Z. U., Al-Abdeli, Y. M., \& Guzzomi, F. G. (2015). Impingement pressure characteristics of swirling and non-swirling turbulent jets. Experimental Thermal and Fluid Science, 68, 722-732. https://doi.org/ 10.1016/j.expthermflusci.2015.07.017

Al-Hadhrami, L. M., Shaahid, S., \& Al-Mubarak, A. A. (2011). Jet impingement cooling in gas turbines for improving thermal efficiency and power density. Advances in Gas Turbine Technology, 191-210. https://doi.org/ 10.5772/22020

Ashforth-Frost, S., Jambunathan, K., \& Whitney, C. (1997). Velocity and turbulence characteristics of a semiconfined orthogonally impinging slot jet. Experimental Thermal and Fluid Science, 14(1), 60-67. https://doi.org/10.1016/S08941777(96)00112-4

Barbosa, F. V., Sousa, S. D., Teixeira, S. F., \& Teixeira, J. C. (2021). Application of taguchi method for the analysis of a multiple air jet impingement system with and without target plate motion. 
International Journal of Heat and Mass Transfer, $\quad 176, \quad 121504$. https://doi.org/10.1016/j.ijheatmasstransfer.202 1.121504

Buzzard, W. C., Ren, Z., Ligrani, P. M., Nakamata, C., \& Ueguchi, S. (2017). Influences of target surface small-scale rectangle roughness on impingement jet array heat transfer. International Journal of Heat and Mass Transfer, $\quad 110, \quad 805-816$. https://doi.org/10.1016/j.ijheatmasstransfer.201 7.03.061

Caliskan, S., Baskaya, S., \& Calisir, T. (2014). Experimental and numerical investigation of geometry effects on multiple impinging air jets. International Journal of Heat and Mass Transfer, 75, 685-703. https://doi.org/10.1016/j.ijheatmasstransfer.201 4.04.005

Çelik, N., \& Haydar, E. (2010). Çarpan dairesel bir jette çarpma bölgesi türbülans şiddetinin is1 transferine etkisi. Isl Bilimi ve Tekniği Dergisi, 30(1), 91-98.

Demircan, T., \& Türkoğlu, H. (2007). Bir yüzeye çarpan osilasyonlu iki boyutlu dikdörtgen hava jetinin sayısal olarak incelenmesi. Isı Bilimi ve Tekniği Dergisi, 27(1), 39-50.

Demircan, T., \& Türkoğlu, H. (2010). Çarpan osilasyonlu jetlerde osilasyon karakteristiklerinin ve çarpma mesafesinin akiş ve isi transferine etkilerinin sayisal olarak incelenmesi. Gazi Üniversitesi Mühendislik Mimarlık Fakültesi Dergisi, 25(4).

Diop, S. N., Dieng, B., \& Senaha, I. (2021). A study on heat transfer characteristics by impinging jet with several velocities distribution. Case Studies in Thermal Engineering, 101111. https://doi.org/10.1016/j.csite.2021.101111

Gelis, K., \& Akyurek, E. F. (2021). Entropy generation of different panel radiator types: Design of experiments using response surface methodology (RSM). Journal of Building Engineering, 41, 102369.

https://doi.org/10.1016/j.jobe.2021.102369

Ianiro, A., \& Cardone, G. (2012). Heat transfer rate and uniformity in multichannel swirling impinging jets. Applied Thermal Engineering, 49, 89-98. https://doi.org/10.1016/j.applthermaleng.2011.1 0.018

Karabulut, K., \& Alnak, D. E. (2020). Değişik şekilde tasarlanan 1sıtılmış yüzeylerin hava jeti çarpmalı soğutulmasının araştırılması. Pamukkale Üniversitesi Mühendislik Bilimleri Dergisi, 26(1), 88-98.
Kilic, M., \& Baskaya, S. (2017). Farklı geometride akış yönlendiriciler ve çarpan jet kullanarak yüksek 1S1 ak1l1 bir yüzeyden olan 1S1 transferinin iyileştirilmesi. Gazi Üniversitesi Mühendislik Mimarlık Fakültesi Dergisi, 25(4), 693-707.

Lam, P. A. K., \& Prakash, K. A. (2017). A numerical investigation and design optimization of impingement cooling system with an array of air jets. International Journal of Heat and Mass Transfer, 108, 880-900. https://doi.org/10.1016/j.ijheatmasstransfer.201 6.12 .017

Maghrabie, H. M. (2021). Heat transfer intensification of jet impingement using exciting jets-A comprehensive review. Renewable and Sustainable Energy Reviews, 139, 110684. https://doi.org/10.1016/j.rser.2020.110684

Monnoyer, F., \& Lochegnies, D. (2008). Heat transfer and flow characteristics of the cooling system of an industrial glass tempering unit. Applied Thermal Engineering, 28(17-18), 2167-2177. https://doi.org/10.1016/j.applthermaleng.2007.1 2.014

Nuntadusit, C., Wae-Hayee, M., Bunyajitradulya, A., \& Eiamsa-Ard, S. (2012). Heat transfer enhancement by multiple swirling impinging jets with twisted-tape swirl generators. International Communications in Heat and Mass Transfer, 39(1), 102-107. https://doi.org/10.1016/j.icheatmasstransfer.201 1.10 .003

Ortega-Casanova, J. (2012). CFD and correlations of the heat transfer from a wall at constant temperature to an impinging swirling jet. International Journal of Heat and Mass Transfer, 55(21-22), 5836-5845.

https://doi.org/10.1016/j.ijheatmasstransfer.201 2.05.079

Ortega-Casanova, J., \& Granados-Ortiz, F. (2014). Numerical simulation of the heat transfer from a heated plate with surface variations to an impinging jet. International Journal of Heat and Mass Transfer, 76, 128-143. https://doi.org/10.1016/j.ijheatmasstransfer.201 4.04 .022

Penumadu, P. S., \& Rao, A. G. (2017). Numerical investigations of heat transfer and pressure drop characteristics in multiple jet impingement system. Applied Thermal Engineering, 110, 1511-1524.

https://doi.org/10.1016/j.applthermaleng.2016.0 9.057

Rao, G. A., Levy, Y., \& Kitron-Belinkov, M. (2009). Heat transfer characteristics of a multiple jet impingement system. In 48th Israeli Aerospace Conference (pp. 5-7), Tel-Aviv. 
Wang, G., Deng, Y., Xu, X., He, X., Zhao, Y., Zou, Y., . . Yue, J. (2016). Optimization of air jet impingement drying of okara using response surface methodology. Food control, 59, 743-749. https://doi.org/10.1016/j.foodcont.2015.06.047

Wannassi, M., \& Monnoyer, F. (2015). Fluid flow and convective heat transfer of combined swirling and straight impinging jet arrays. Applied Thermal Engineering, 78, 62-73. https://doi.org/10.1016/j.applthermaleng.2014.1 2.043

Yakut, R., Yakut, K., Yeşildal, F., \& Karabey, A. (2016). Experimental and numerical investigations of impingement air jet for a heat sink. Procedia Engineering, 157, 3-12. https://doi.org/10.1016/j.proeng.2016.08.331

Yesildal, F., Ozakin, A. N., \& Yakut, K. (2021). Optimization of operational parameters for a photovoltaic panel cooled by spray cooling. Engineering Science and Technology, an International Journal. https://doi.org/10.1016/j.jestch.2021.04.002

Yildizeli, A., \& Cadirci, S. (2020). Multi-objective optimization of multiple impinging jet system through genetic algorithm. International Journal of Heat and Mass Transfer, 158, 119978. https://doi.org/10.1016/j.ijheatmasstransfer.202 0.119978 